\title{
Modeling and Stability Analysis of Wedge Clutch System
}

\author{
Jian Yao, Li Chen, and Chengliang Yin \\ National Lab of Automotive Electronics and Control, Shanghai Jiao Tong University, Shanghai 200240, China \\ Correspondence should be addressed to Li Chen; li.h.chen@sjtu.edu.cn
}

Received 13 January 2014; Accepted 11 April 2014; Published 5 May 2014

Academic Editor: Yuri Vladimirovich Mikhlin

Copyright (C) 2014 Jian Yao et al. This is an open access article distributed under the Creative Commons Attribution License, which permits unrestricted use, distribution, and reproduction in any medium, provided the original work is properly cited.

\begin{abstract}
A wedge clutch with unique features of self-reinforcement and small actuation force was designed. Its self-reinforcement feature, associated with different factors such as the wedge angle and friction coefficient, brings different dynamics and unstable problem with improper parameters. To analyze this system, a complete mathematical model of the actuation system is built, which includes the DC motor, the wedge mechanism, and the actuated clutch pack. By considering several nonlinear factors, such as the slip-stick friction and the contact or not of the clutch plates, the system is piecewise linear. Through the stability analysis of the linearized system in clutch slipping phase, the stable condition of the designed parameters is obtained as $\alpha>\arctan \left(\mu_{c}\right)$. The mathematical model of the actuation system is validated by prototype testing. And with the validated model, the system dynamics in both stable and unstable conditions is investigated and discussed in engineering side.
\end{abstract}

\section{Introduction}

With the rising demand of improving vehicle economy, the electrification is a clear tendency in modern transmission system. Various electrmechanical components have been designed for clutch actuators in automatic manual transmission [1], dual clutch transmission [2,3], and so forth. Among these, the wedge-based clutch actuator, featuring selfreinforcement function [4], offers good opportunity to obtain large normal force by small actuation force. Therefore, the wedge clutch can be space-saving and energy-saving and satisfy the requirement of automotive electronics applications relying on the low voltage batteries $[5,6]$. The clutch actuator using rack and pinion as wedge mechanism was proposed for automated manual transmission [7]. A wedge mechanism with worm shaft and worm gear was studied for automatic transmission [8].

The magnitude of the friction force generated by the wedge actuator is associated with factors such as the wedge angle, friction coefficient, actuation force, and the clutch slipping speed [8]. Theoretically, the self-reinforcement ratio can be positive or negative and can be larger or less than 1 , depending on the value of those factors. In order to gain satisfactory performance, the wedge geometry and friction interface characteristics need modest design, and the actuator force needs to be controlled carefully considering the clutch slipping speed. For the driveline dynamics, the most important thing is to be stable, for unstability leads toserious safty problems for vehicles. Unfortunately, the wedge brake system can be unstable if improper parameters are applied [9]. Stability analysis is necessary for the wedge-based clutch actuation system since it affects the longitude dynamic of the vehicle driveline and unstable situation may also occur in automatic transmission with wedge clutches. However, no literature reports the research yet.

Stability analysis methods for the various systems in engineering have been introduced by many researchers. In linear system, the eigenvalue analysis was commonly used [10, 11], and the Routh criterion reduced the computational cost by investigating the characteristic equations $[12,13]$. For the nonlinear system, the Lyapunov theory was introduced in $[14,15]$, and proper linearization methods were also used for easy analysis, such as the linear matrix inequalities (LMIs) technical [16] and center manifold theorem [17]. Besides that, both mathematical and experimental methods have been applied to analyze the stability of wedge-based actuators. In [18], a wedge brake was modeled and the roots of characteristic equation were investigated to obtain the stable 


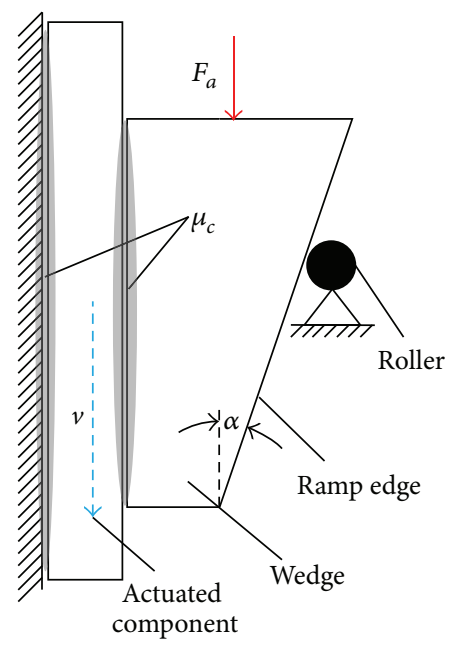

(a) Structure

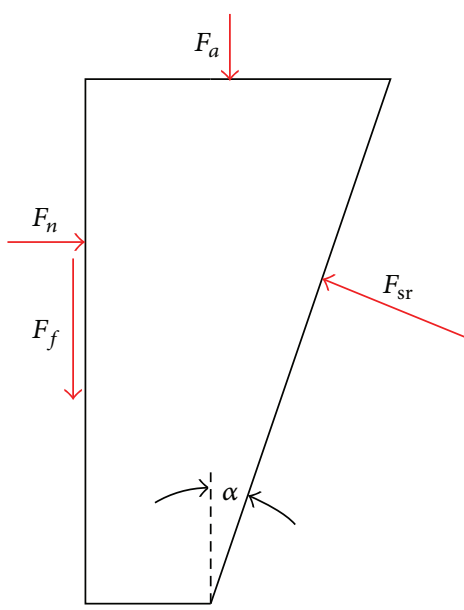

(b) Force analysis

Figure 1: Principle of the wedge-based clutch actuation.

condition. But its actuator (e.g., motor or hydraulic) was not included in the model and there were no experiments. Since the experiments can better reflect the system dynamics, a prototype of a single motor wedge brake was completed, and the stable range is tested under different friction coefficient [19]. A dynamometer test was conducted for a cross wedge brake, and the results showed the stable dynamics [20]. However, the dynamics in unstable condition did not show.

The objective of this paper is to investigate the stable conditions and system dynamics through modeling and stability analysing the wedge clutch actuation system. To do this, a complete model is built which includes the DC motor, the wedge mechanism, and the actuated clutch pack. By considering several nonlinear factors, such as the stickslip friction and contact or not of the clutch plates, the model is piecewise linear during clutch engagement. Then, compared with the other stages, clutch slipping stage has the possibility of being unstable. Therefore, in this stage, the stability analysis of the system is performed with the Routh criterion to obtain its stable conditions. A prototype of the wedge clutch actuation system is completed by replacing one of the hydraulic actuated clutches in an AT. The test results validate the mathematical model and the designed parameters. With the validated model, both the stable and unstable situations according to the stability conditions are investigated to obtain its different dynamic results.

The rest of this paper is organized as follows. In Section 2, the working principle of the wedge mechanism is described. In Section 3, the dynamic model of the wedge-based clutch actuation system is built with the nonlinear factors. Based on the model, linearization within the clutch slipping stage and stability analysis are performed in Section 4. Section 5 describes the prototype test to validate the model and investigates the dynamics of wedge clutch in stable and unstable situations. Conclusions are summarized in Section 6.

\section{Principle of the Wedge Mechanism}

For better understanding, the principle of the wedge mechanism is described first in this section. Figure 1(a) shows the structure of the wedge mechanism, which includes a supporting roller, a wedge with a ramp edge, and an actuated component. There are friction surfaces between the wedge and actuated component. The driving force is applied on the short edge of the wedge. And $v$ represents the relative velocity of the actuated component with respect to the wedge.

Figure 1(b) shows the force analysis of the wedge. $F_{a}$ represents the driving force by the actuator (e.g., DC motor), $F_{n}$ represents the normal force between the wedge and actuated component, $F_{\text {sr }}$ represents the reaction force from the supporting roller, $F_{f}$ represents the friction force between the wedge and actuated component, and $\alpha$ represents the wedge angle.

If $v$ is downward, the friction force $F_{f}$ applied on wedge acts in the same direction which is expressed as

$$
F_{f}=\mu_{c} F_{n}
$$

where $\mu_{c}$ represents the dynamic friction coefficient between the wedge and actuated component. The force equilibrium equations of the wedge are

$$
\begin{gathered}
F_{a}+F_{f}-F_{\mathrm{sr}} \sin \alpha=0, \\
F_{n}-F_{\mathrm{sr}} \cos \alpha=0 .
\end{gathered}
$$

By defining the ratio between the friction force and actuation force as the self-reinforcement feature, its function is obtained from (1) and (2) as follows:

$$
i_{f}=\frac{F_{f}}{F_{a}}=\frac{\mu_{c}}{\tan \alpha-\mu_{c}} .
$$




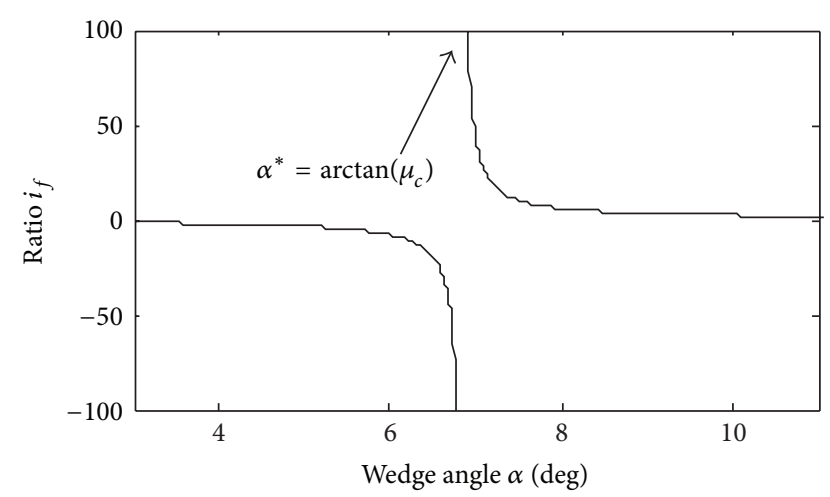

FIGURE 2: Relationship between self-reinforcement ratio and wedge angle.

Equation (3) shows that the ratio $i_{f}$ is related to the friction coefficient $\mu_{c}$ and the ramp angle $\alpha$. If $\mu_{c}$ and $\alpha$ are both constants, the relationship is linear.

The friction coefficient depends on the selected clutch plates. Through choosing the different wedge angle, the relationship between the ratio and angle can be obtained in Figure 2.

When $\alpha>\arctan \left(\mu_{c}\right)$, the ratio $i_{f}>0$, which means that the direction of $F_{a}$ is the same as that of $F_{f}$. On the contrary, when $\alpha<\arctan \left(\mu_{c}\right)$, the ratio $i_{f}<0$, which means that the direction of $F_{a}$ is opposite to that of $F_{f}$. This situation implies that the actuator needs to pull the wedge instead of pushing it to keep its equilibrium. Furthermore, it is shown in Figure 2 that there is a critical wedge angle $\alpha^{*}=\arctan \left(\mu_{c}\right)$, which makes the ratio $i_{f}$ tend to infinity. The infinity of the ratio means that even a small actuation force can produce a huge friction force and normal force on the actuated component. The friction force can help to actuate the wedge, which seems to enlarge the actuation force. This unique phenomenon is named "self-reinforcement" feature.

Another assumption, if the moving direction of the actuated component is upward in Figure 1, is the direction of the friction force that is reversed. The relationship in (3) is replaced by (4), in which the magnitude of the friction force is always smaller than that of the actuation force. So the actuation force is weakened in this case, which should be avoided in the design of a wedge-based actuator. Thus, the self-reinforcement feature of the wedge mechanism is related to the moving direction of the actuated component:

$$
i_{f}=\frac{F_{f}}{F_{a}}=-\frac{\mu_{c}}{\tan \alpha+\mu_{c}} .
$$

\section{Mechanical Model}

By using the wedge mechanism, the clutch actuation system is designed with a DC motor and worm mechanism. Its design process and working principle are described in [21]. To analyze the system behavior of the wedge clutch, its mathematical model including the nonlinear factors is built in this section. The nonlinear factors include the slip-stick change of the friction and separate or contact of the clutch plates.

The schematic of the actuation system is shown in side view and top view in Figure 3. The DC motor, worm shaft, worm gear, wedge block, and clutch plate are modeled, respectively. The friction plates in clutch pack are simplified as a single plate because their motions are identical, so are the steel plates. The three wedge elements on the wedge block are simplified as one element since they can be considered as identical in terms of structure, force, and motion. The original return spring of the hydraulic clutch is used to preload a spring force in the actuation system. So, during the clutch engagement, the worm shaft is contacted with the driving side of the gear to engage the wedge clutch; and during the clutch disengagement, the pretightening force will push back the components automatically which keeps the driving side of the gear contacting with the worm shaft. Therefore, the backlash issue of the worm mechanism is weakened with this design and will not be considered mainly in the following.

3.1. DC Motor. The dynamics of the DC motor are described as follows [22], with the motor current $I_{m}$ as the system input:

$$
\begin{gathered}
J_{m} \ddot{\theta}_{m}=T_{m}-T_{\mathrm{ws}}-c_{m} \dot{\theta}_{m}, \\
T_{m}=K_{t} I_{m} .
\end{gathered}
$$

In (5), $J_{m}$ is the inertia of the rotor, $\theta_{m}$ is the rotating angle of the rotor, $c_{m}$ is the damping coefficient, $T_{\text {ws }}$ represents the load torque from the worm shaft, and $T_{m}$ is the motor torque which is regarded as proportional with the motor current by the torque constant $K_{t}$.

3.2. Shaft Connector. The shaft connector is modeled as a torsional spring, which generates a force calculated as

$$
T_{\mathrm{ws}}=k_{\mathrm{sc}}\left(\theta_{m}-\theta_{\mathrm{ws}}\right) \text {, }
$$

where $K_{\mathrm{sc}}$ represents the torsional stiffness of the shaft connector and $\theta_{\mathrm{ws}}$ is the rotating angle of the worm shaft.

3.3. Worm Shaft and Worm Gear. The angular speed ratio $n$ between the worm shaft and worm gear is defined as

$$
n=\frac{\dot{\theta}_{\mathrm{ws}}}{\dot{\theta}_{\mathrm{wg}}} \text {. }
$$

The equivalent dynamic equation of the worm shaft and worm gear can be written as

$$
J_{\mathrm{wg}} \ddot{\theta}_{\mathrm{wg}}=T_{\mathrm{wg}}-T_{\mathrm{wb}}-c_{\mathrm{wg}} \dot{\theta}_{\mathrm{wg}} .
$$

In (9), $J_{w g}$ represents the equivalent moment inertia of worm shaft and worm gear, $\theta_{\mathrm{wg}}$ is the rotating angle of worm gear, $c_{\mathrm{wg}}$ is the damping coefficient, $T_{\mathrm{wb}}$ represents the resistance torque from the wedge block, and the driving torque $T_{\mathrm{wg}}$ is calculated as

$$
T_{\mathrm{wg}}=n T_{\mathrm{ws}}
$$




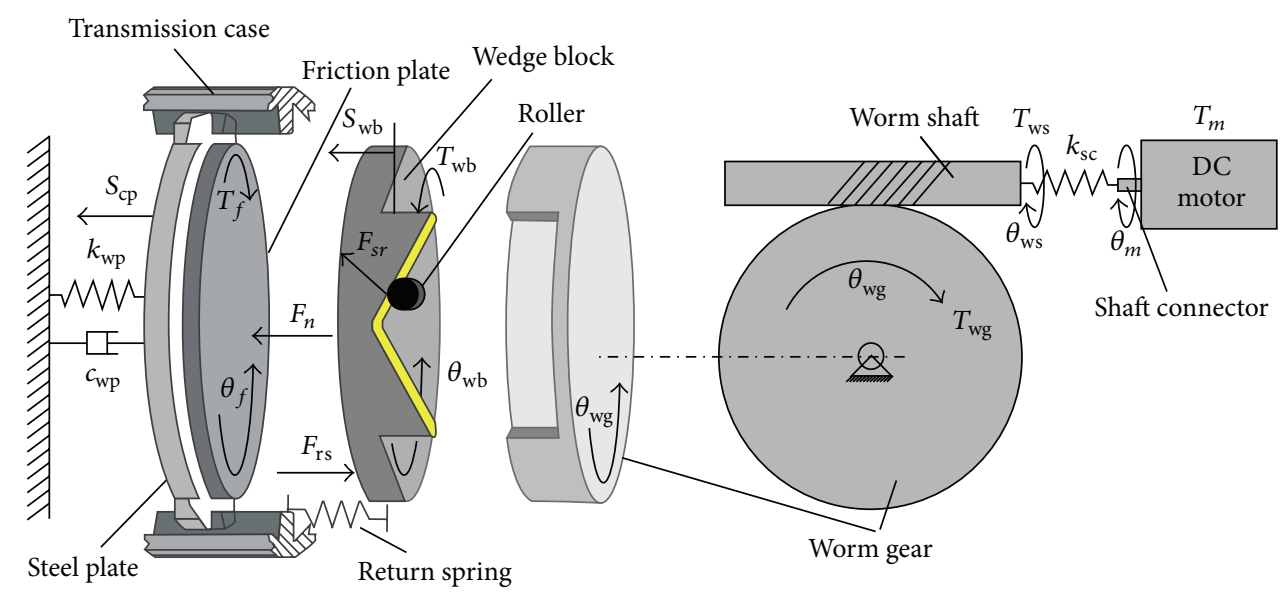

(a) Side view

(b) Top view

FIGURE 3: Schematic of the wedge-based clutch actuator.

3.4. Wedge Block. The movement of the wedge block along the axis can be written as

$$
M_{\mathrm{wb}} \ddot{S}_{\mathrm{wb}}=F_{\mathrm{sr}} \cos \alpha-F_{\mathrm{rs}}-F_{n}-c_{s_{-} \mathrm{wb}} \dot{S}_{\mathrm{wb}},
$$

where $M_{\mathrm{wb}}$ is the mass of the wedge block, $S_{\mathrm{wb}}$ is the axial displacement, $c_{s_{-} w b}$ is the damping coefficient of axial displacement, $F_{\mathrm{sr}}$ represents the reaction force from the supporting roller, $F_{\mathrm{rs}}$ represents the resistance of the return spring, and $F_{n}$ is the normal force.

Since the return spring force $F_{\mathrm{rs}}$ keeps almost constant in the working range of $\left[\begin{array}{ll}S_{\mathrm{wb} 0} & S_{\mathrm{wb} 1}\end{array}\right], F_{\mathrm{rs}}$ can be considered as a constant value in this study.

The rotation of the wedge block around the axis can be written as

$$
J_{\mathrm{wb}} \ddot{\theta}_{\mathrm{wb}}=T_{\mathrm{wb}}+T_{f}-F_{\mathrm{sr}} R_{\mathrm{cp}} \sin \alpha-c_{\mathrm{wb}} \dot{\theta}_{\mathrm{wb}},
$$

where $J_{\mathrm{wb}}$ is the moment inertia of the wedge block, $\theta_{\mathrm{wb}}$ is the rotating angle, $c_{\mathrm{wb}}$ is the damping coefficient, $T_{\mathrm{wb}}$ represents the driving force applied on the wedge block, $T_{f}$ represents the friction force between wedge block and friction plate, and $R_{\mathrm{cp}}$ is the equivalent radius of clutch plates.

Since the wedge block moves against the supporting roller, the translational and rotational movements are subject to the constraint:

$$
S_{\mathrm{wb}}=\theta_{\mathrm{wb}} R_{\mathrm{cp}} \tan \alpha .
$$

Therefore, by substituting $S_{\mathrm{wb}}$ by the above expression, the dynamic equation is derived as

$$
\begin{aligned}
& \left(1+\tan \alpha^{2}\right) J_{\mathrm{wb}} \ddot{\theta}_{\mathrm{wb}} \\
& \quad=T_{\mathrm{wb}}+T_{f}-F_{n} \tan \alpha R_{\mathrm{cp}}-F_{\mathrm{rs}} \tan \alpha R_{\mathrm{cp}}-c_{w_{\mathrm{eq}}} \dot{\theta}_{\mathrm{wb}} .
\end{aligned}
$$

When the wedge clutch is filling the clearance, the wedge block does not contact with the friction plate; that is, $F_{n}=0$ and $T_{f}=0$. The above dynamic equation can be rewritten as

$$
\left(1+\tan \alpha^{2}\right) J_{\mathrm{wb}} \ddot{\theta}_{\mathrm{wb}}=T_{\mathrm{wb}}-F_{\mathrm{rs}} \tan \alpha R_{\mathrm{cp}}-c_{w_{\mathrm{eq}}} \dot{\theta}_{\mathrm{wb}},
$$

in which the equivalent damping coefficient $c_{w_{-} \text {eq }}$ is calculated by

$$
c_{w_{-} \mathrm{eq}}=c_{\mathrm{wb}}+\tan \alpha R_{\mathrm{cp}} c_{s_{-} \mathrm{wb}} .
$$

3.5. Clutch Plates. Each of the clutch plates, which can be the friction plate or steel plate, has two degrees of freedom of motion, that is, moving along and rotating around the central axis. The moving dynamics is decided by the actuation system, and the rotating dynamics is decided by the connected driveline. Therefore, the moving dynamics is discussed in this paper, since only the actuation system is considered. Apart from those, the relationship between the normal force $F_{n}$ and the friction torque $T_{f}$ is also discussed in this section, which will affect the dynamics of wedge block.

The moving dynamics along the axis of the clutch plates is written as

$$
M_{\mathrm{cp}} \ddot{S}_{\mathrm{cp}}=F_{n}-k_{\mathrm{wp}} S_{\mathrm{cp}}-c_{\mathrm{wp}} \dot{S}_{\mathrm{cp}}
$$

where $M_{c p}$ is the total mass of the clutch plates, $S_{c p}$ is the axial displacement, $c_{\mathrm{wp}}$ is the damping coefficient of axial displacement, and $K_{\mathrm{wp}}$ is the stiffness of the wave plate.

$F_{n}$ is equal to zero before the clutch plates pass through the clearance filling phase; that is,

$$
F_{n}=0 \quad \text { when } S_{\mathrm{wb}}<S_{\mathrm{wb} 0} .
$$

The Coulomb friction model is used for the friction torque $T_{f}$ [23]. So when the clutch is slipping, the friction torque is given by

$$
T_{f}=\operatorname{sign}(\omega) \mu_{c} R_{\mathrm{cp}} F_{n},
$$

where $\omega$ is the slipping speed of the friction plate and $\mu_{c}$ is the dynamic friction coefficient.

When the clutch is sticking, the friction plate is locked. Consequently, the friction torque cannot be altered by the normal force $F_{n}$ anymore. The switch from the slipping model 
to the sticking model is determined by the condition $\omega=0$ with the constraint that the friction torque is smaller than the static friction torque:

$$
-\mu_{s} R_{\mathrm{cp}} F_{n} \leq T_{c} \leq \mu_{s} R_{\mathrm{cp}} F_{n}
$$

where $\mu_{s}$ is the static friction coefficient.

\section{Linearization and Stability Analysis}

Since the wedge mechanism may introduce instability issue to the applications [9], this section conducts stability analysis in order to find out the stable condition for the wedge clutch actuation system. To linearize the model, an appropriate operation point has to be found, and this point has to be at key operation range of the system [24]. During the actuation process, the clutch can be open (filling phase), slipping, or locked as described in the previous section. And the wedge clutch model is a piecewise linear system during these stages. In open stage, the actuation system is a common damping system since there is no contact between wedge and friction plate. And in locked stage, the actuation system can be regarded as a single body without relative motion. Therefore, both of the stages are stable. However, the slipping stage is critical for the controllability of the wedge clutch. In this stage, the wedge block dynamics is affected by the friction torque $T_{f}$ as expressed in (14), and $T_{f}$ is related to the slipping speed $\omega$, friction coefficient $\mu_{c}$, and wedge angle $\alpha$ as expressed in (19) and (20); consequently, the stability of the wedge block dynamics in slipping stage becomes a concern.

The relevant dynamical equations are (5), (9), (14), and (17).

Since the worm gear is splined with the wedge block, the following holds:

$$
\dot{\theta}_{\mathrm{wg}}=\dot{\theta}_{\mathrm{wb}}
$$

Considering that the friction plate contacts with the steel plate and the wedge block, the following holds:

$$
S_{\mathrm{cp}}=S_{\mathrm{wb}}
$$

Since only the slipping stage is concerned, $T_{f}$ can be calculated by $T_{c}$ on the basis of Coulomb friction model. Substitution of (6), (7), and (21) into (5) yields

$$
J_{m} \ddot{\theta}_{m}=k_{t} I_{m}-k_{\mathrm{sc}} \theta_{m}+k_{\mathrm{sc}} n \theta_{\mathrm{wb}}-c_{m} \dot{\theta}_{m} .
$$

Substitution of (13), (20), (21), and (22) into (9), (14), and (17) yields one equation as below:

$$
\begin{aligned}
& {\left[\left(1+\tan \alpha^{2}\right) J_{\mathrm{wb}}+J_{\mathrm{wg}}-\left(\mu_{\mathrm{c}}-\tan \alpha\right) \tan \alpha R_{\mathrm{cp}}{ }^{2} M_{\mathrm{cp}}\right] \ddot{\theta}_{\mathrm{wb}}} \\
& =\left[\left(\mu_{c}-\tan \alpha\right) \tan \alpha R_{\mathrm{cp}}{ }^{2} c_{\mathrm{wp}}-c_{w_{-} \mathrm{eq}}-c_{\mathrm{wg}}\right] \dot{\theta}_{\mathrm{wb}} \\
& +\left[\left(\mu_{c}-\tan \alpha\right) \tan \alpha R_{\mathrm{cp}}{ }^{2} k_{\mathrm{sc}}-n^{2} k_{\mathrm{sc}}\right] \theta_{\mathrm{wb}}+n k_{\mathrm{sc}} \theta_{m} \\
& \quad-F_{\mathrm{rs}} \tan \alpha R_{\mathrm{cp}}-\left(\mu_{c}-\tan \alpha\right) R_{\mathrm{cp}} k_{\mathrm{wp}} S_{\mathrm{wb} 0} .
\end{aligned}
$$

TABLE 1: Routh table.

\begin{tabular}{lcc}
\hline$\zeta^{4}$ & $a_{0}$ & $a_{2}$ \\
$\zeta^{3}$ & $a_{1}$ & $a_{3}$ \\
$\zeta^{2}$ & $a_{21}=\frac{a_{1} a_{2}-a_{0} a_{3}}{a_{1}}$ & $a_{22}=\frac{a_{1} a_{4}}{a_{1}}=a_{4}$ \\
$\zeta^{1}$ & $a_{31}=\frac{a_{21} a_{3}-a_{1} a_{4}}{a_{21}}$ & \\
$\zeta^{0}$ & $a_{41}=\frac{a_{31} a_{22}}{a_{31}}$ & \\
\hline
\end{tabular}

Defining the state variable as $X=\left(\begin{array}{llll}\dot{\theta}_{m} & \theta_{m} & \dot{\theta}_{\mathrm{wb}} & \theta_{\mathrm{wb}}\end{array}\right)^{T}$ and the control input as $U=I_{m}$, the state equation is derived as

$$
\dot{X}=A \cdot X+B \cdot U+C
$$

in which

$$
\begin{gathered}
A=\left(\begin{array}{cccc}
-\frac{c_{m}}{J_{m}} & \frac{-k_{\mathrm{sc}}}{J_{m}} & 0 & \frac{n k_{\mathrm{sc}}}{J_{m}} \\
1 & 0 & 0 & 0 \\
0 & \frac{n k_{\mathrm{sc}}}{J} & A_{33} & A_{34} \\
0 & 0 & 1 & 0
\end{array}\right), \quad B=\left(\begin{array}{c}
\frac{k_{t}}{J_{m}} \\
0 \\
0 \\
0
\end{array}\right), \\
C=\left(\begin{array}{c}
\left(\tan \alpha-\mu_{c}\right) k_{\mathrm{wp}} R_{\mathrm{cp}} S_{\mathrm{wb} 0}-\tan \alpha R_{\mathrm{cp}} F_{\mathrm{rs}} \\
\frac{J}{0}
\end{array}\right),
\end{gathered}
$$

and $J=J_{\mathrm{wg}}+\left(1+\tan ^{2} \alpha\right) J_{\mathrm{wb}}-\left(\mu_{c}-\tan \alpha\right) \tan \alpha R_{\mathrm{cp}}{ }^{2} M_{\mathrm{cp}}$, $A_{33}=\left(\left(\mu_{c}-\tan \alpha\right) \tan \alpha R_{\mathrm{cp}}{ }^{2} c_{\mathrm{wp}}-c_{\mathrm{wb}}-c_{\mathrm{wg}}-\tan \alpha R_{\mathrm{cp}} c_{s_{-} \mathrm{wb}}\right) / J$, $A_{34}=\left(\left(\mu_{c}-\tan \alpha\right) k_{\mathrm{wp}} R_{\mathrm{cp}}^{2} \tan \alpha-n^{2} k_{\mathrm{sc}}\right) / J$.

The characteristic polynomials are expressed as

$$
\begin{gathered}
\operatorname{det}(\zeta I-A)=0, \quad \zeta \in \mathbb{C}, \\
a_{0} \zeta^{4}+a_{1} \zeta^{3}+a_{2} \zeta^{2}+a_{3} \zeta^{1}+a_{4}=0 .
\end{gathered}
$$

According to Routh criterion, a linear system is stable if all the coefficients $a$ of (28) and all the elements of Routh series are positive. The Routh series of the system are shown in Table 1.

According to (26), (27), and (28), the coefficients are deducted as follows:

$$
\begin{gathered}
a_{0}=1, \\
a_{1}=-A_{33}+\frac{c_{m}}{J_{m}},
\end{gathered}
$$




$$
\begin{gathered}
a_{2}=-A_{33} \frac{c_{m}}{J_{m}}-A_{34}+\frac{k_{\mathrm{sc}}}{J_{m}}, \\
a_{3}=-A_{34} \frac{c_{m}}{J_{m}}-A_{33} \frac{k_{\mathrm{sc}}}{J_{m}}, \\
a_{4}=-\frac{k_{\mathrm{sc}}}{J_{m}} A_{34}-\frac{n^{2} k_{\mathrm{sc}}^{2}}{J J_{m}}=-\frac{\left(\mu_{c}-\tan \alpha\right) k_{\mathrm{wp}} k_{\mathrm{sc}} R_{\mathrm{cp}}{ }^{2} \tan \alpha}{J J_{m}}, \\
a_{21}=\frac{a_{1} a_{2}-a_{0} a_{3}}{a_{1}}=\frac{A_{33}}{c_{m} / J_{m}-A_{33}} A_{34} \\
+\frac{c_{m} / J_{m}}{c_{m} / J_{m}-A_{33}} \frac{k_{\mathrm{sc}}}{J_{m}}-A_{33} \frac{c_{m}}{J_{m}}, \\
a_{31}=\frac{a_{21} a_{3}-a_{1} a_{4}}{a_{21}}=-A_{34} \frac{c_{m}}{J_{m}}-A_{33} \frac{k_{\mathrm{sc}}}{J_{m}} \\
-\frac{\left(\left(\mu_{c}-\tan \alpha\right) k_{\mathrm{wp}} k_{\mathrm{sc}} R_{\mathrm{cp}}{ }^{2} \tan \alpha / J J_{m}\right)\left(c_{m} / J_{m}-A_{33}\right)}{a_{21}}, \\
a_{41}=\frac{a_{31} a_{22}}{a_{31}}=a_{4}=-\frac{\left(\mu_{c}-\tan \alpha\right) k_{\mathrm{wp}} k_{\mathrm{sc}} R_{\mathrm{cp}}{ }^{2} \tan \alpha}{J J_{m}} .
\end{gathered}
$$

Assumption 1. The wedge angle is bigger than the critical value, so as to keep the positive self-reinforcement ratio. Consider

$$
\tan \alpha-\mu_{c}>0
$$

Proof. According to (26), (29), and (30), $a_{4}=a_{41}>0$ and $A_{33}, A_{34}<0$, since all the other parameters in equations have the positive values. Then, by substituting the $A_{33}, A_{34}<0$ and $\tan \alpha-\mu_{c}>0$ in (29), we can obtain that $a_{1}, a_{2}, a_{3}, a_{21}, a_{31}>0$. Therefore, all the coefficients $a$ in (29) are positive.

Remark 2. The results show that the (30) is a sufficient condition for the stable system.

Assumption 3. The wedge angle is smaller than the critical value, so the self-reinforcement ratio is negative:

$$
\tan \alpha-\mu_{c}<0
$$

Proof. According to the (29) and (31), $a_{0}>0$ but $a_{4}<0$. So there are both positive and negative coefficients of the Routh series, which means that the system has at least one positive root. So the system is unstable [25].

Remark 4. The results show that (31) is a sufficient condition for the unstable system.

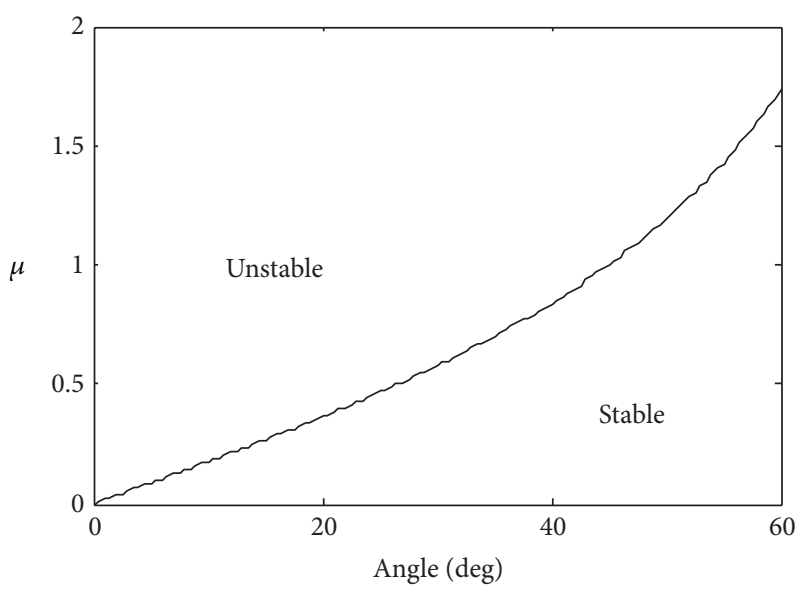

FIGURE 4: Stable region of the wedge clutch.

Theorem 5. If a proposition is true, its converse-negative proposition is also true.

Conclusion. According to the Remark 4 and Theorem 5, we can obtain that $\tan \alpha-\mu_{c}>0$ is a necessary condition for the stable system. And then by combining Remark 2, we can finally get the conclusion that (30) is the necessary and sufficient condition for the stable system (26).

And by considering the wedge angle and friction coefficient as the variables, the stable region is plotted in Figure 4. The dividing line is $\mu_{c}=\tan (\alpha)$.

The stability analysis above is for the linearized system under the key operation point with the assumption of constant friction coefficient value. The classical ideal Coulomb friction model is used for the stability analysis with linear method. However, the real friction of the wet clutch including Stribeck and viscous factors is different from Coulomb friction. So, the stability condition in (30) is a guideline for choosing the suitable wedge angle under the steady friction coefficient. And with the stability analysis at different friction coefficients, the selection of wedge angle needs to make the maximum friction coefficient value satisfy the condition.

\section{Results and Discussion}

A prototype of the wedge clutch with designed parameters is completed. And the experiments are performed to validate the mathematical model. Then, using the validated mathematical model, the dynamics of the wedge clutch in stable and unstable conditions is investigated and discussed.

5.1. Prototype of the Actuator. The designed wedge clutch is integrated in the six-speed front wheel drive (FWD) AT to replace one of the hydraulic actuated clutches as the validation platform in Figure 5. The integration work into the transmission is omitted here since we focus on the validation of the actuation system. The rated power and torque of the DC motor are $80 \mathrm{~W}$ and $0.5 \mathrm{Nm}$, respectively. Three force sensors 


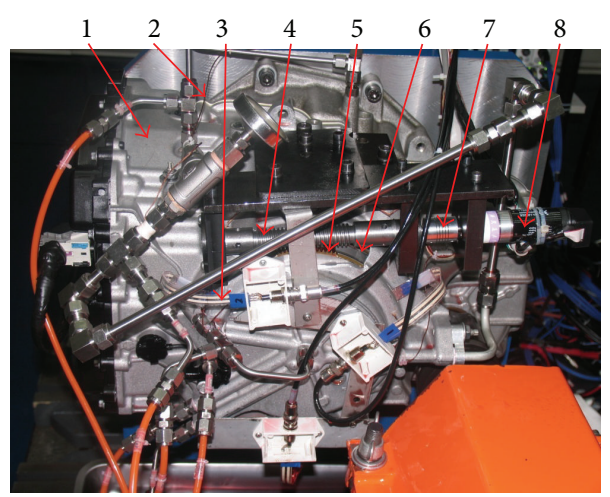

(a) Picture of prototype
(1) Transmission case
(2) Thermocouple
(3) Force sensor
(4) Worm shaft
(5) Worm gear
(6) Wedge block
(7) Shaft connector
(8) DC motor
(9) Roller
(10) Support ring
(11) Friction plate
(12) Steel plate

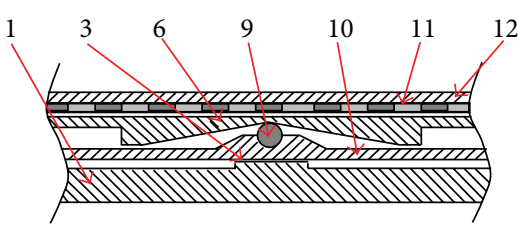

(b) Force sensor installation

Figure 5: Prototype of the wedge clutch.

are used to measure the normal force on the clutch plates. The force range is up to $2000 \mathrm{~N}$ for each sensor, so the total is up to $6000 \mathrm{~N}$. The response time of the force sensor is less than $5 \mu \mathrm{sec}$ and its linearity (error) is within $\pm 3 \%$. The thickness of the force sensor is only $0.208 \mathrm{~mm}$, which allows direct installation between the fixed case and roller supporting ring as in Figure 5(b). Therefore, the reacting normal force on the roller of each wedge mechanism is fully applied on the force sensor, and sum of the three force sensor signals can represent the total normal force on clutch plates. Besides that, the transferred clutch torque can be calculated from the transmission input/output torque with ratio since there will be torque sensors during the dyno test.

5.2. Experimental Validation for the Actuator. To validate the mathematical model of the wedge clutch, three cases studies are presented in the following. First, a step command current is applied to the actuation system to investigate the tracking performance between the simulation results and experimental results. Then, both with and without self-reinforcement situations of the wedge clutch are performed to validate its self-reinforcement function by comparing the results.

5.2.1. Case I: Step Response. The actuation system generates normal force on the friction plate by a certain amount of motor current. The motor current is given as a step function with the amplitude of 3A, as shown in Figure 6(a). The resultant motor speed, motor displacement, and clutch normal force are illustrated in Figure 6. The parameters of the wedge clutch during the simulation model are listed in Table 2.

It can be seen that the simulation results match the experimental results well. The motor speed increases rapidly in the early stage because no resistant force comes from the clutch plates before the wedge block contacts the clutch friction plate (filling phase). After that, the motor speed increases slowly because the motor load is increasing gradually due to the spring force from the wave plate once the wedge block contacts the clutch friction plate. Along with the increasing of the motor displacement, the spring force of the wave plate becomes large. Consequently, the motor speed decreases until
TABLE 2: Parameter values of the wedge-based clutch actuator.

\begin{tabular}{lc}
\hline Symbol & Value \\
\hline$J_{m}$ & $0.0004 \mathrm{~kg} \cdot \mathrm{m}^{2}$ \\
$J_{\mathrm{wg}}$ & $0.0036 \mathrm{~kg} \cdot \mathrm{m}^{2}$ \\
$J_{\mathrm{wb}}$ & $0.0082 \mathrm{~kg} \cdot \mathrm{m}^{2}$ \\
$M_{\mathrm{wb}}$ & $0.87 \mathrm{~kg}$ \\
$M_{\mathrm{cp}}$ & $0.75 \mathrm{~kg}$ \\
$K_{t}$ & $0.105 \mathrm{Nm} / \mathrm{A}$ \\
$c_{m}$ & $0.00008 \mathrm{Nm} \cdot \mathrm{s} / \mathrm{rad}$ \\
$c_{\mathrm{wg}}$ & $9.5 \mathrm{Nm} \cdot \mathrm{s} / \mathrm{rad}$ \\
$c_{\mathrm{wb}}$ & $10 \mathrm{Nm} \cdot \mathrm{s} / \mathrm{rad}$ \\
$c_{s_{-} \mathrm{wb}}$ & $120 \mathrm{~N} \cdot \mathrm{s} / \mathrm{m}$ \\
$c_{\mathrm{wp}}$ & $100 \mathrm{~N} \cdot \mathrm{s} / \mathrm{m}$ \\
$k_{\mathrm{sc}}$ & $20 \mathrm{Nm} / \mathrm{rad}$ \\
$k_{\mathrm{wp}}$ & $1.3 \times 10 e 6 \mathrm{~N} / \mathrm{m}$ \\
$n$ & 164 \\
$R_{\mathrm{cp}}$ & $0.105 \mathrm{~m}$ \\
$S_{\mathrm{wb} 0}$ & $0.002 \mathrm{~m}$ \\
$F_{\mathrm{rs}}$ & $200 \mathrm{Nm}$ \\
$\alpha$ & $10 \mathrm{degree}$ \\
$\mu_{c}$ & 0.12 \\
$\mu_{s}$ & 0.15 \\
\hline
\end{tabular}

the motor stops. During this process, the normal force on the clutch friction plate increases from zero to $1834 \mathrm{~N}$ in $0.45 \mathrm{~s}$.

5.2.2. Case II: With Self-Reinforcement Situation. The principle analysis of the wedge mechanism shows that its selfreinforcement function depends on the moving direction of the actuated component (the rotating direction of friction plate for the wedge clutch). Therefore, according to the rotating direction, one of the wedge surfaces of the dualwedge group in Figure 3 can be selected to ensure the self-reinforcement effect. Inversely, the other wedge surface corresponds to the without self-reinforcement situation.

Figure 7 shows the simulation and experimental results of the with self-reinforcement situation. The motor current is 


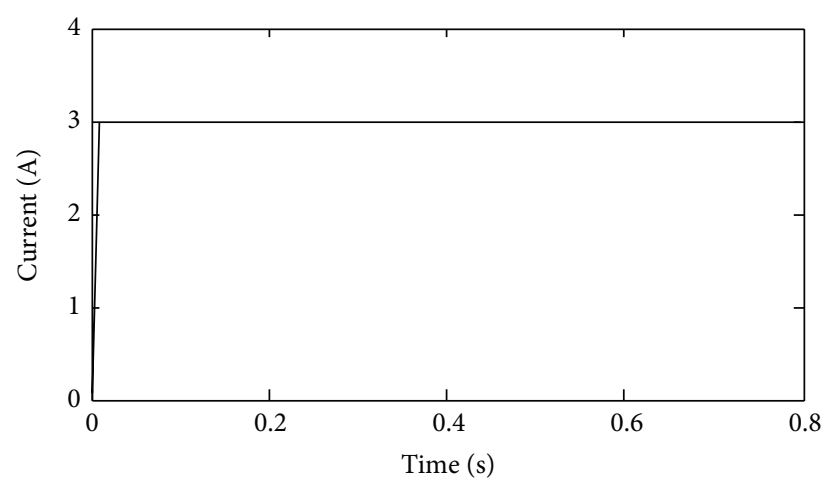

(a) Motor current $I_{m}$

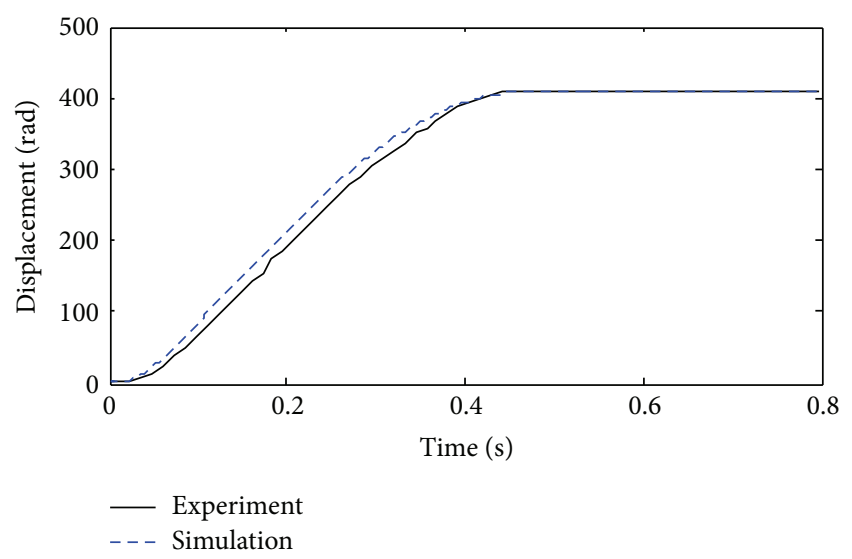

(c) Motor angular displacement $\theta_{m}$

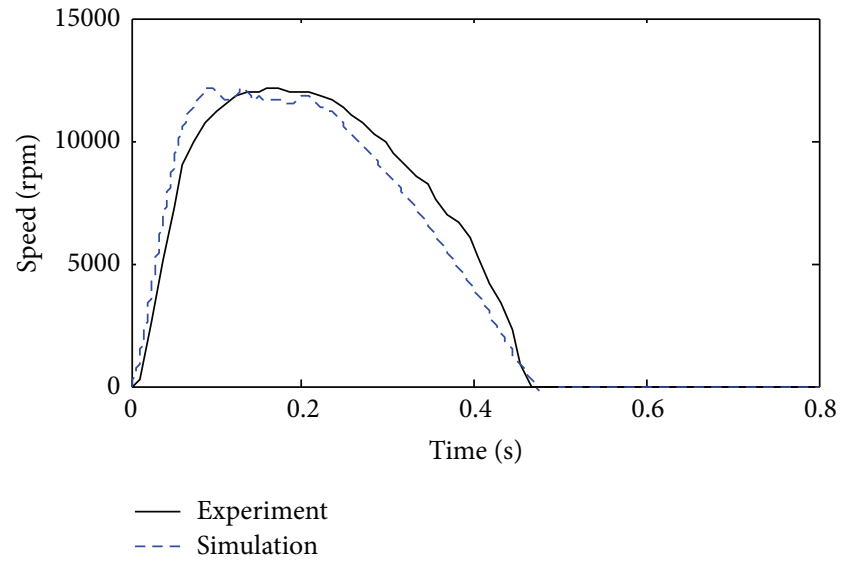

(b) Motor speed $\dot{\theta}_{m}$

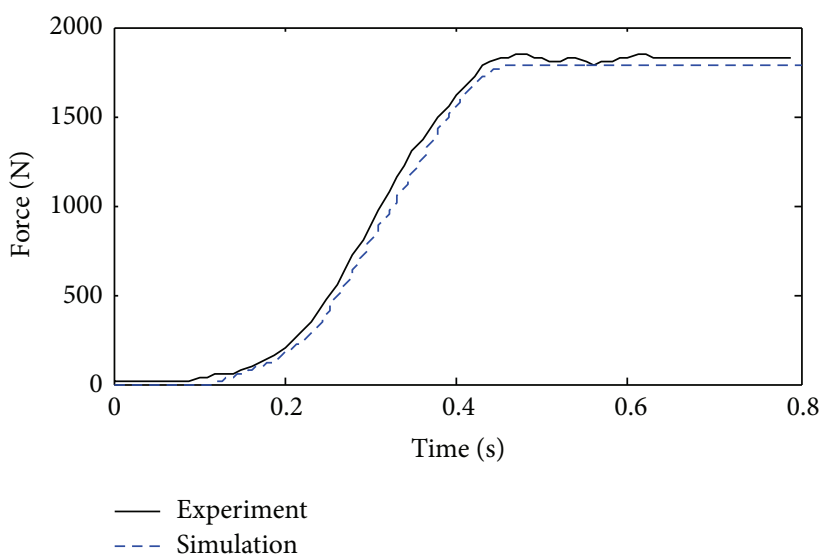

(d) Normal force $F_{n}$ on friction plate

FIgURE 6: Model validation of the wedge-based actuator.

controlled carefully to drive the actuator to engage the clutch, and the control process is a typical oncoming clutch engagement in AT. From the speed information in Figure 7(b), the actuator moves fast at the beginning to complete the clutch clearance as quickly as possible. After that, the speed is reduced to keep an almost steady state and engage the clutch smoothly. Finally, the actuator moves further to increase the normal force again and ensure the transmitted torque capacity. Therefore, the position and normal force curves have a two-step shape as shown in Figures 7(c) and 7(d). Besides that, the well matching between the simulation and experimental curves again validates the models.

5.2.3. Case III: Without Self-Reinforcement Situation. By applying an opposite motor current to the actuation system, the other wedge surface is selected which corresponds to the without self-reinforcement situation. The simulation and experimental results are shown in Figure 8. The speed and position information of the actuator also have the opposite directions in Figures 8(b) and 8(c). The two-step shape of the normal force curve is similar in comparison with that of with self-reinforcement situation. However, its value is much smaller as shown in Figure 8(d). The gap between the normal force curves of the two situations validates the selfreinforcement function of the wedge mechanism.

5.3. Stability Case Study and Discussion. The self-reinforcement effect of the wedge mechanism depends on the relationship between the wedge angle and friction coefficient in (3). And according to the stable rule in Figure 4, several points, representing stable or unstable situations, are selected for simulation in the mathematical model.

5.3.1. Case I: $\mu_{c}=0.12$ and $\alpha=7^{\circ} \sim 10^{\circ}$ (in Stable Region). Figure 9 provides the results with $\mu_{c}=0.12$ and $\alpha=7.3^{\circ}$, which is in stable region. With a step current of $3 \mathrm{~A}$ to actuate the wedge clutch, the normal force on clutch plates ramps up quickly and then keeps constantly at about $20000 \mathrm{~N}$ as shown in Figure 9(b). After 3.5 s, the command current reduces back to zero, and the normal force also decreases to zero. Therefore, the system is controllable and stable.

By varying the value of wedge angle from $7^{\circ}$ to $10^{\circ}$ while keeping the friction coefficient as 0.12 , the simulation results with the same step current curve are obtained in Figure 10. 


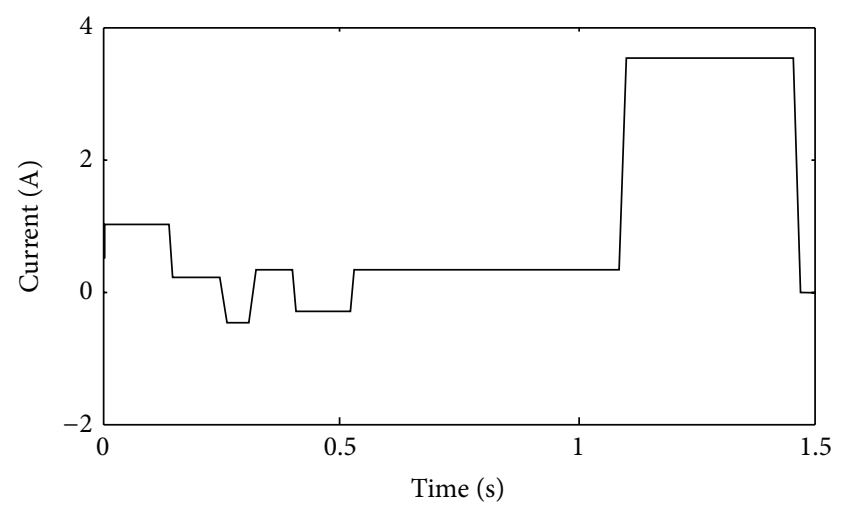

(a) Motor current $I_{m}$

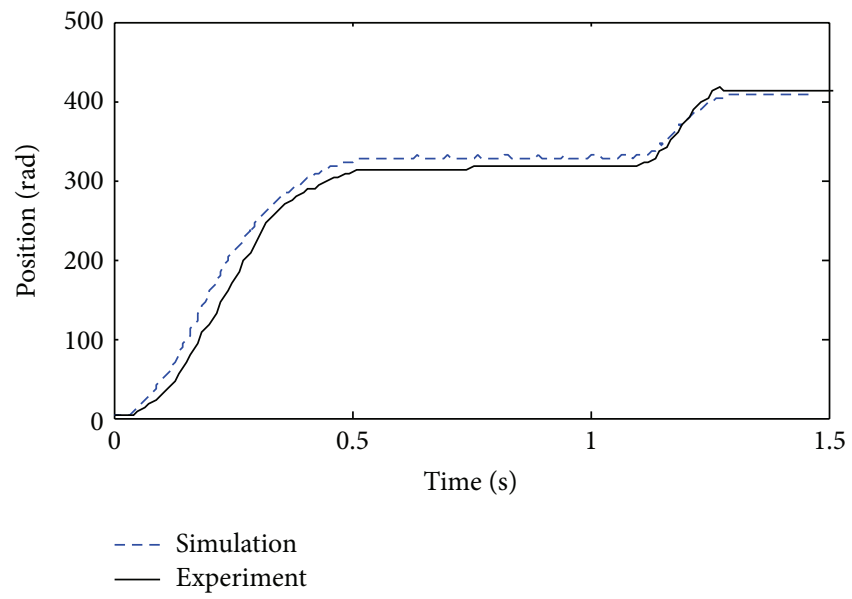

(c) Motor angular displacement $\theta_{m}$

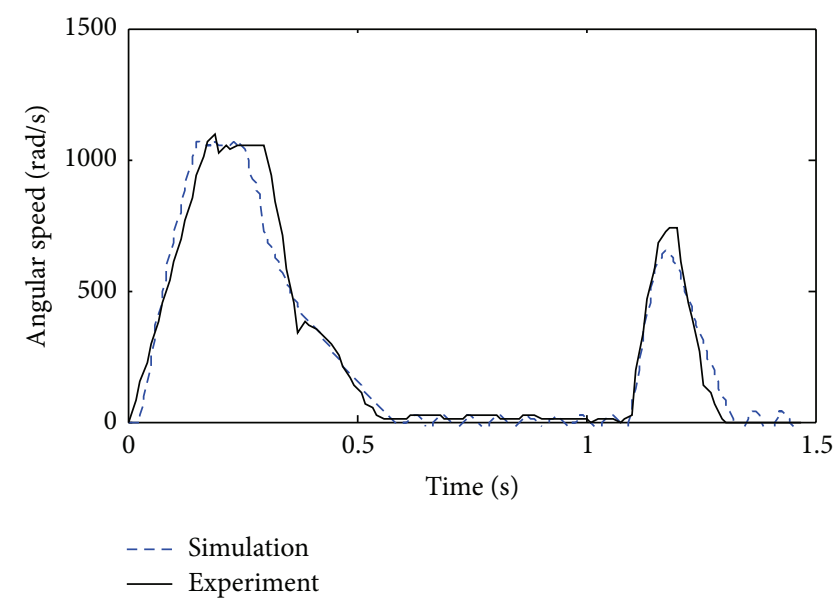

(b) Motor speed $\dot{\theta}_{m}$

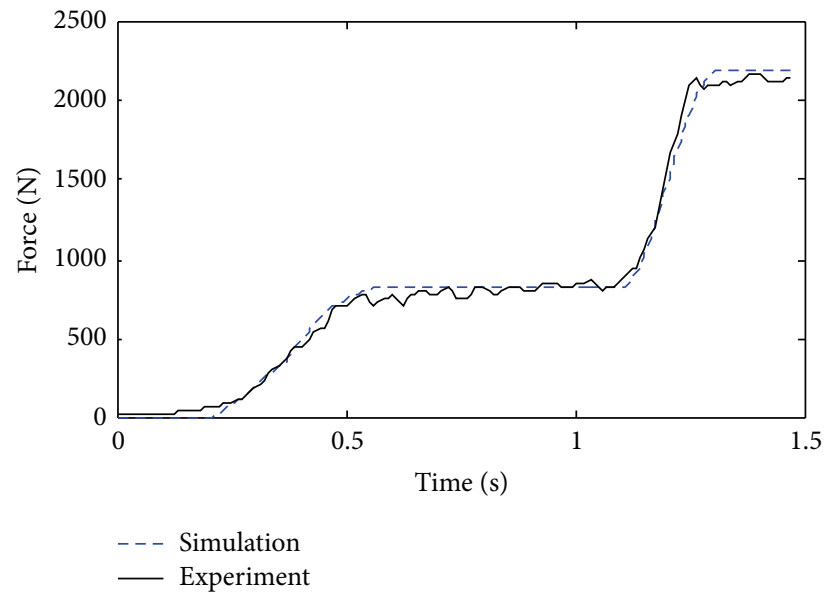

(d) Normal force $F_{n}$ on friction plate

FIGURE 7: With self-reinforcement of the wedge-based actuator.

All the curves of normal force represent stable situations. While with smaller wedge angle, the normal force becomes bigger. This is due to the larger self-reinforcement ratio.

5.3.2. Case II: $\mu_{c}=0.12$ and $\alpha=6^{\circ} \sim 6.8^{\circ}$ (in Unstable Region). By selecting the value of wedge angle from $6^{\circ}$ to $6.8^{\circ}$ and with the same friction coefficient, these conditions are in the unstable region of Figure 4. Then a same step current of $3 \mathrm{~A}$ is controlled to actuate the wedge clutch, and the simulation results are shown in Figure 11. The curves show that the applied normal force on clutch plate increases continuously to infinity even though the command current returns to zero after $3.5 \mathrm{~s}$, which means that the wedge clutch engages by itself and will not release. The system goes in self-lock state.

In this self-lock situation, the ratio $i<0$ according to the (3), which means that a negative actuation force is needed to pull the wedge for keeping its equilibrium. In the following simulation, a negative current is controlled to pull the actuation system after the positive step current.
The simulation results are shown in Figure 12, and the parameters are selected as $\mu_{c}=0.12$ and $\alpha=6.5^{\circ}$.

With the 1A positive current step at first, the normal force on clutch plates increases quickly due to the self-lock situation of the wedge mechanism. Then after a negative current step at $0.3 \mathrm{~s}$, the normal force stops increasing. By optimal adjusting the negative current value, the equilibrium state of the wedge clutch seems to be realized and obtains a steady state normal force in the figure. However, with even a small increasing or decreasing of the current value, the wedge clutch leaves its equilibrium state easily. A small increment current value causes the normal force to reduce to zero quickly, and a small decrement current value causes the normal force to increase to infinity again as in Figure 11. In engineering side, the infinity normal force in self-lock situation means the wedge mechanism engages by itself more and more tightly until damaging the components. On the contrary, by increasing the actuation force to pull the wedge mechanism, the zero normal force means the wedge block is pulled out thoroughly once the actuation force exceeds the equilibrium value. 


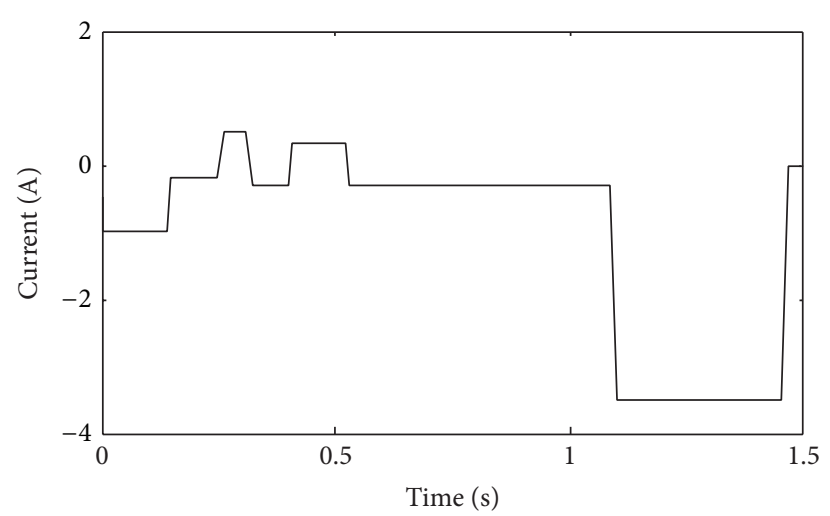

(a) Motor current $I_{m}$

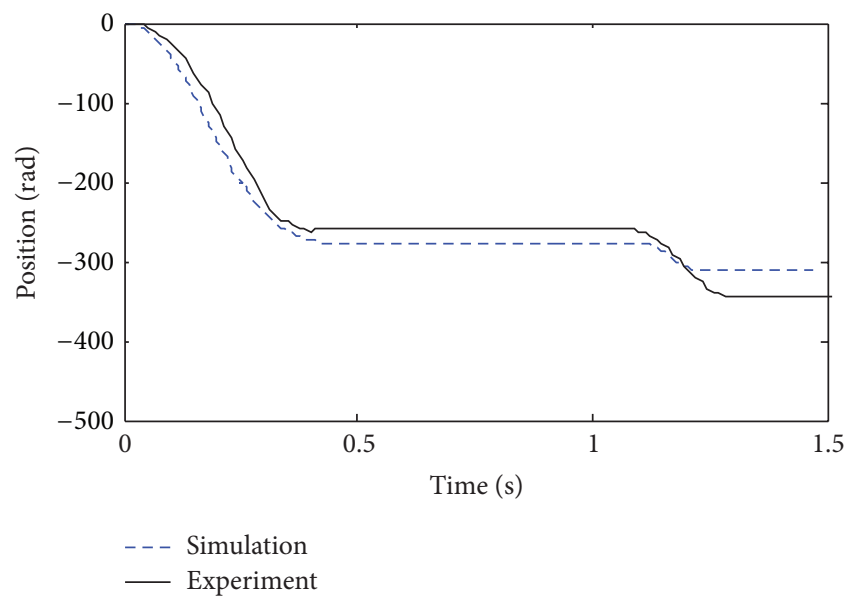

(c) Motor angular displacement $\theta_{m}$

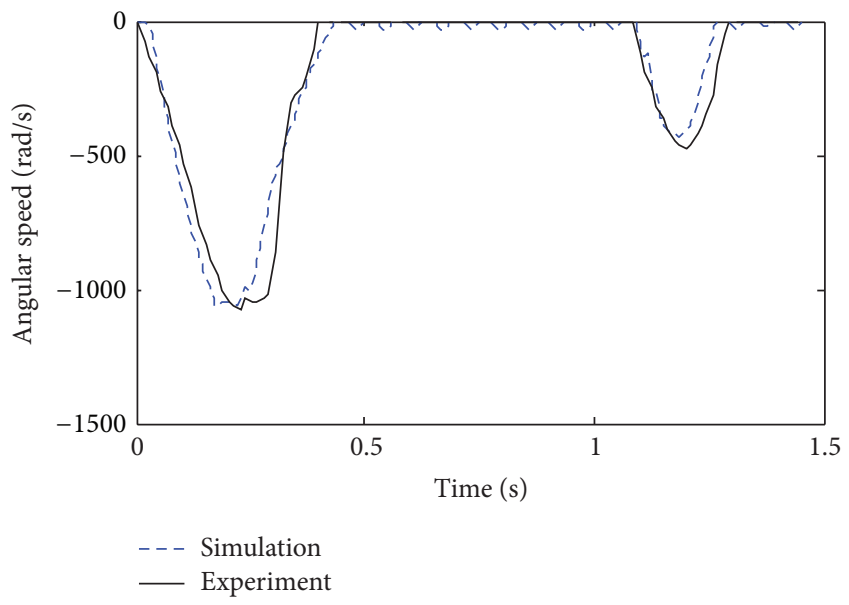

(b) Motor speed $\dot{\theta}_{m}$

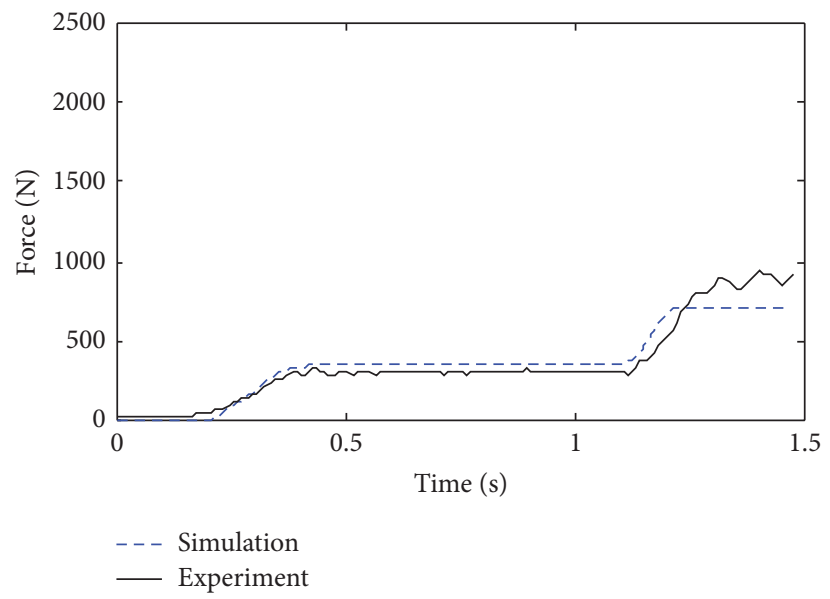

(d) Normal force $F_{n}$ on friction plate

FIGURE 8: Without self-reinforcement of the wedge-based actuator.

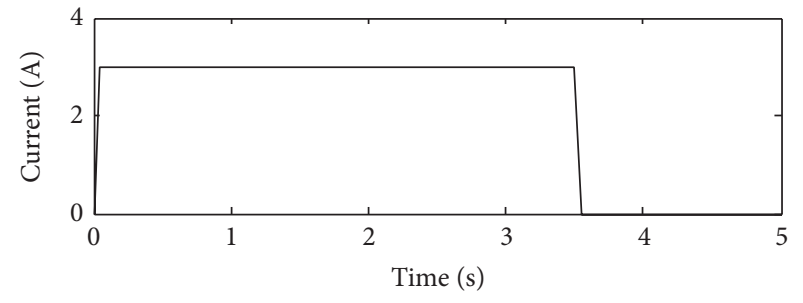

(a) Motor current $I_{m}$

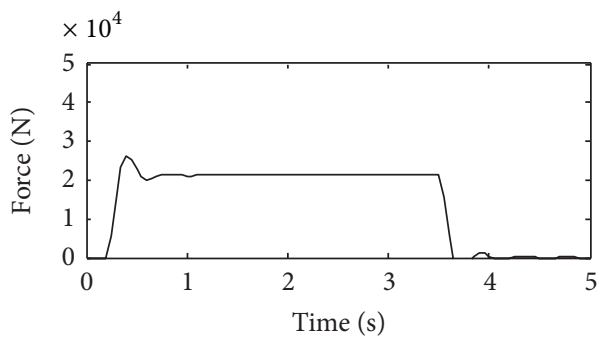

(b) Normal force $F_{n}$ on friction plate

FIGURE 9: Stable simulation with $\mu_{c}=0.12$ and $\alpha=7.3^{\circ}$.

So this equilibrium state of the wedge clutch is not stable, since it is easy to become unstable by small perturbation.

Finally, we can summarize that the simulation results comply well with the stability analysis. And when $\alpha>$ $\arctan \left(\mu_{c}\right)$, the wedge clutch is stable and easier for control. Therefore, the design rule for the wedge angle is that it should be greater than $\arctan \left(\mu_{c}\right)$ but be close to $\arctan \left(\mu_{c}\right)$ as much as possible.

\section{Conclusions}

The wedge-based clutch actuation system with self-reinforcement feature brings stability problem and different dynamic behavior. To analyze this system, a complete mathematical model is built including its DC motor, wedge mechanism, and clutch pack. And the model is linearized by considering the clutch slipping stage with steady state friction coefficient. 


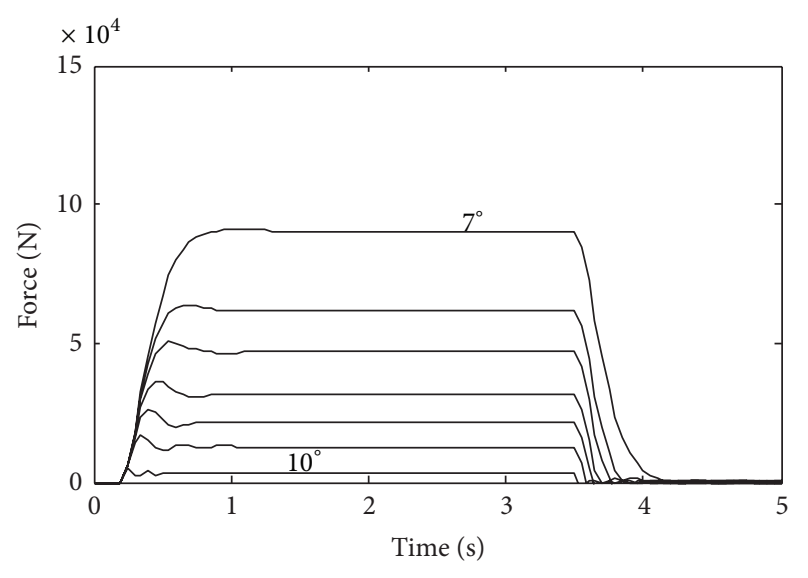

FIGURE 10: Stable situation with different wedge angle.

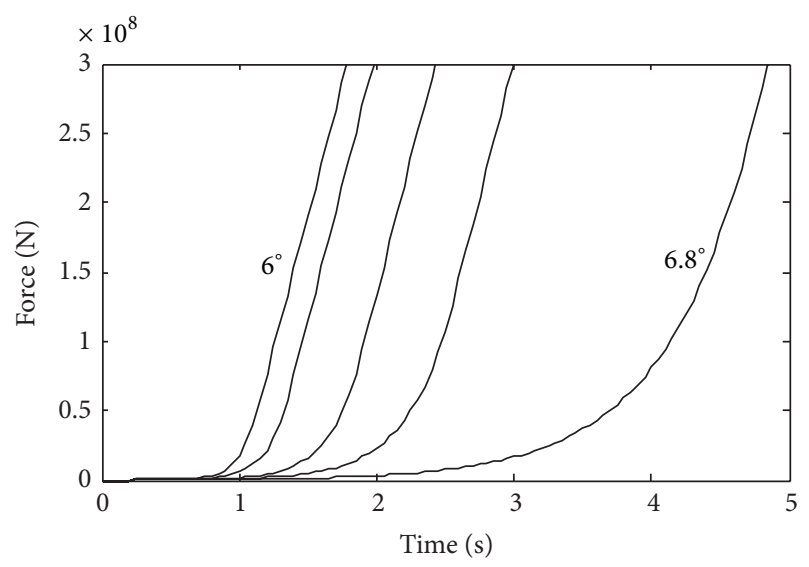

FIGURE 11: Self-lock situation with different wedge angle.

Through using the Routh criterion, the stability condition is obtained as $\alpha>\arctan \left(\mu_{c}\right)$. Then, the prototype testing validates the mathematical model with its designed parameters. And with the validated model, the simulation results show that in the stable region, the wedge clutch is easy for control. And in unstable region, the wedge is either engaged by itself continuously until damaging the components or pulled out thoroughly without contact force. So a design instruction is found that the wedge angle should be greater than $\arctan \left(\mu_{c}\right)$ and be close to $\arctan \left(\mu_{c}\right)$ as much as possible for the large self-reinforcement ratio.

Although the stability analysis for the linearized system is performed in this paper, the wedge clutch system is highly nonlinear due to friction, backlash and, and so forth. Furthermore, in combination with the self-reinforcement feature of wedge mechanism which depends on the friction coefficient and status of contact or not, these nonlinearities make the system really complicated. So, in the following step work, the highly nonlinear and complicated system will be analyzed based on the knowledge of this paper.

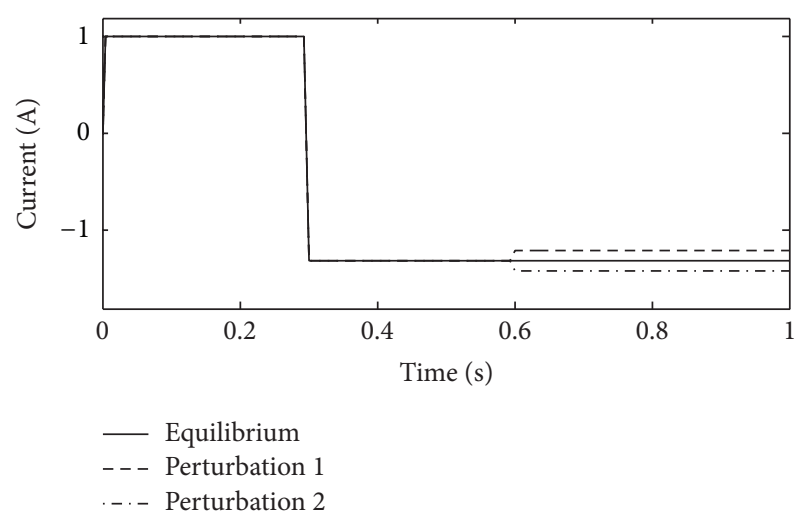

(a) Motor current $I_{m}$

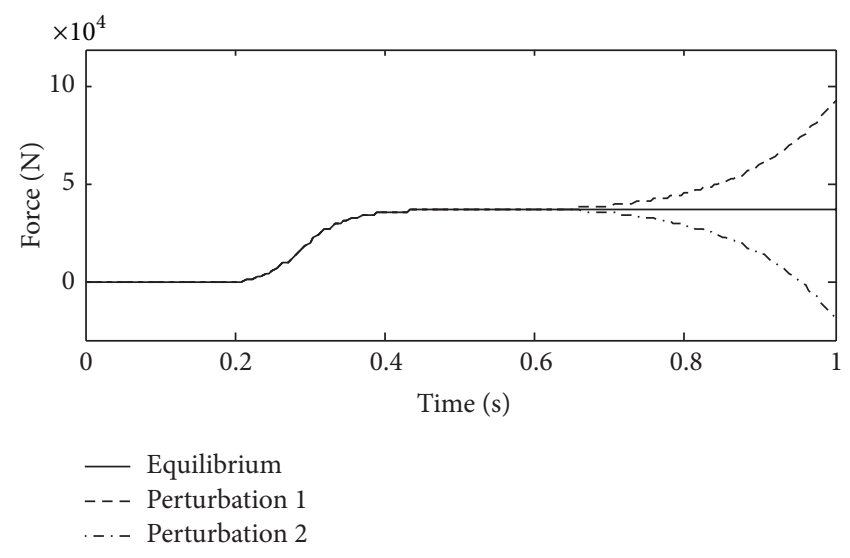

(b) Normal force $F_{n}$ on friction plate

FIGURE 12: Self-lock situation with negative current.

\section{Nomenclature}

c: Damping coefficient

F: $\quad$ Force

$F_{n}: \quad$ Normal force

$i_{f}$ : Ratio of friction force over actuation force

$I_{m}: \quad$ Motor current

$J$ : $\quad$ Moment of inertia

$k: \quad$ Stiffness

$K_{t}: \quad$ Torque constant of motor

$M: \quad$ Mass

$n: \quad$ Angular speed ratio between worm shaft and worm gear

$R: \quad$ Radius

$S: \quad$ Axial displacement

$T: \quad$ Torque

$T_{s}: \quad$ Maximum stiction torque

$T_{\text {stick }}:$ Stiction torque

$v: \quad$ Slipping speed

$\alpha$ : Wedge angle

$\mu_{c}:$ Dynamic friction coefficient

$\mu_{s}:$ Static friction coefficient

$\omega$ : $\quad$ Slipping speed of friction interface

$\theta$ : Angular displacement 
$\theta_{f}:$ Angular displacement of friction plate

$\zeta$ : Matrix characteristic value.

\section{Subscript}

$\begin{array}{ll}\text { a: } & \text { Actuation } \\ \text { cp: } & \text { Clutch plate } \\ f: & \text { Friction } \\ m: & \text { Motor } \\ \text { rs: } & \text { Return spring } \\ \text { sc: } & \text { Shaft connector } \\ \text { sr: } & \text { Supporting roller } \\ \text { s_wb: } & \text { Wedge block in translational direction } \\ \text { wb: } & \text { Wedge block } \\ \text { wg: } & \text { Worm gear } \\ \text { wp: } & \text { Wave plate } \\ \text { ws: } & \text { Worm shaft. }\end{array}$

\section{Conflict of Interests}

The authors declare that there is no conflict of interests regarding the publication of this paper.

\section{Acknowledgments}

The authors would like to thank Dr. Yu Dong and Mr. Ying Huang from China Science Lab of General Motors Company for hardware and technical support. The authors are also grateful to Dr. Chunhao Joseph Lee and Dr. Chi-kuan Kao from the R\&D of General Motors Company for providing the valuable technical support and suggestions. This work was supported by the Transmission Group of GM R\&D (Project no. RD-07-313) and Chinese National Science Foundation for the support on this project (Grant no. 51105244).

\section{References}

[1] H. Liu, X. Chen, P. Cao, and Q. Zhang, "Modelling and Analysis of a Novel Mechanism for EMT Actuator," Applied Mechanics and Materials, vol. 321-324, pp. 46-50, 2013.

[2] U. Wagner, R. Berger, M. Ehrlich et al., "Electromotoric actuators for double clutch transmissions," in Proceedings of the 8th LuK Symposium, 2006.

[3] J. Wheals, A. Turner, K. Ramsay et al., "Double Clutch Transmission (DCT) using multiplexed linear actuation technology and dry clutches for high efficiency and low cost," SAE Technical Paper 2007-01-1096, 2007.

[4] J. Yao, L. Chen, C. L. Yin et al., "Modeling of a wedge clutch in an automatic transmission," SAE Technical Paper 2010-01-0186, 2010.

[5] A. Turner and K. Ramsay, "Review and development of eectromechanical actuators for improved transmission control and efficiency," SAE Transactions, vol. 113, pp. 908-919, 2004.

[6] N. R. Trevett, X-By-Wire, New Technologies for $42 \mathrm{~V}$ Bus Automobile of the Future, South Carolina Honors College, 2002.

[7] J. Kim and S. B. Choi, "Design and modeling of a clutch actuator system with self-energizing mechanism," IEEE/ASME Transactions on Mechatronics, vol. 16, no. 5, pp. 953-966, 2011.
[8] J. Yao, L. Chen, C. L. Yin et al., "Experimental validation of a wedge clutch in automatic transmissions," in Proceedings of the International Conference on Advanced Vehicle Technologies and Integration, Changchun, China, 2012.

[9] R. Roberts, M. Schaut, H. Hartmann et al., "Modelling and validation of the mechatronic wedge brake," SAE Transactions, vol. 112, pp. 2376-2386, 2003.

[10] P. Liu, H. Zheng, C. Cai et al., "Analysis of disc brake squeal using the complex eigenvalue method," Applied Acoustics, vol. 68, no. 6, pp. 603-615, 2007.

[11] M. Trichês Júnior, S. N. Y. Gerges, and R. Jordan, "Analysis of brake squeal noise using the finite element method: a parametric study," Applied Acoustics, vol. 69, no. 2, pp. 147-162, 2008.

[12] K. Shin, M. J. Brennan, J. E. Oh, and C. J. Harris, "Analysis of disc brake noise using a two-degree-of-freedom model," Journal of Sound and Vibration, vol. 254, no. 5, pp. 837-848, 2002.

[13] J. Kang, C. M. Krousgrill, and F. Sadeghi, "Comprehensive stability analysis of disc brake vibrations including gyroscopic, negative friction slope and mode-coupling mechanisms," Journal of Sound and Vibration, vol. 324, no. 1-2, pp. 387-407, 2009.

[14] Z. Y. Liu, J. W. Gao, and Q. Zheng, "Robust clutch slip con-troller design for automatic transmission," Proceedings of the Institution of Mechanical Engineers D: Journal of Automobile Engineering, vol. 225, no. 8, pp. 989-1005, 2011.

[15] B. Gao, H. Chen, Y. Hu, and K. Sanada, "Nonlinear feedforwardfeedback control of clutch-to-clutch shift technique," Vehicle System Dynamics, vol. 49, no. 12, pp. 1895-1911, 2011.

[16] D. Chen and H. Yu, "Stability analysis of state saturation 2D discrete time-delay systems based on F-M model," Mathematical Problems in Engineering, vol. 2013, Article ID 749782, 9 pages, 2013.

[17] S. Yang and J. Yu, "Stability analysis and variational integrator for real-time formation based on potential field," Mathematical Problems in Engineering, vol. 2014, Article ID 602424, 13 pages, 2014.

[18] L. Balogh, T. Streli, H. Nemeth, and L. Palkovics, "Modelling and simulating of self-energizing brake system," Vehicle System Dynamics, vol. 44, no. 1, pp. 368-377, 2006.

[19] J. Fox, R. Roberts, C. Baier-Welt et al., "Modeling and control of a single motor electronic wedge brake," SAE Technical Paper 2007-01-0866, 2007.

[20] J. G. Kim, M. J. Kim, and J. K. Kim, "Developing of electronic wedge brake with cross wedge," SAE Technical Paper 2009-010856, 2009.

[21] J. Yao, L. Chen, F. Liu et al., "Experimental and control study of slipping decay time of a wedge clutchinan automatic transmission," in Proceedings of the ASME Dynamic Systems and Control Conference, Fort Lauderdale, Fla, USA, October 2012.

[22] G. G. Rigatos, "Adaptive fuzzy control of DC motors using state and output feedback," Electric Power Systems Research, vol. 79, no. 11, pp. 1579-1592, 2009.

[23] S. J. Cull and R. W. Tucker, "On the modelling of Coulomb friction," Journal of Physics A: Mathematical and General, vol. 32, no. 11, pp. 2103-2113, 1999.

[24] G. Obinata and B. Anderson, Model Reduction for Control System Design, Communication and Control Engineering, Springer, Berlin, Germany, 2000.

[25] J. A. Pereda, L. A. Vielva, A. Vegas, and A. Prieto, "Analyzingthe stability of the FDTD technique by combining the von neumann method with the Routh-Hurwitz criterion," IEEE Transactions on Microwave Theory and Techniques, vol. 49, no. 2, pp. 377-381, 2001 


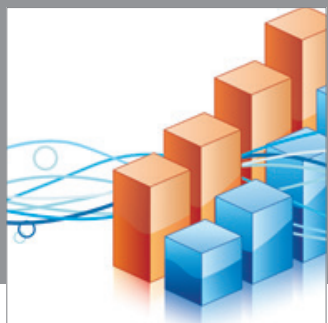

Advances in

Operations Research

mansans

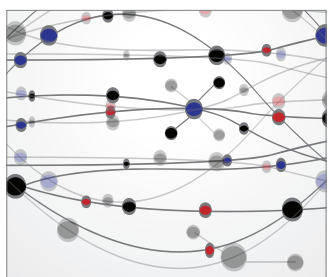

The Scientific World Journal
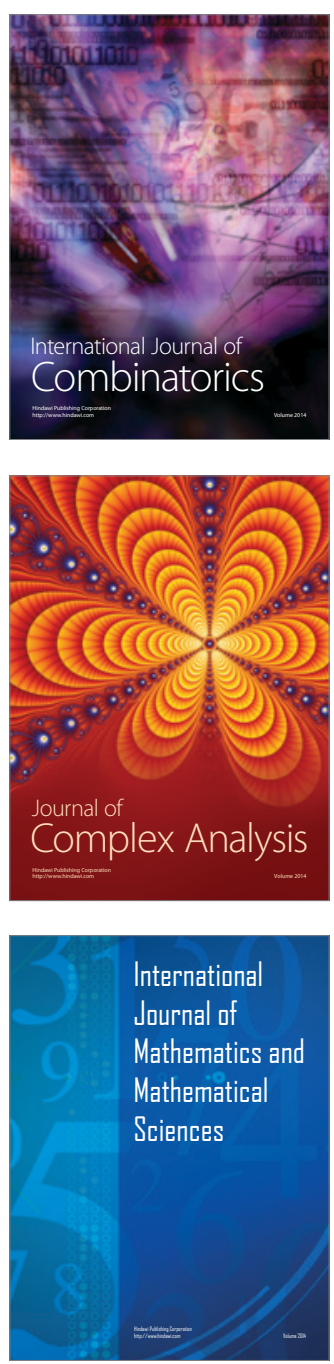
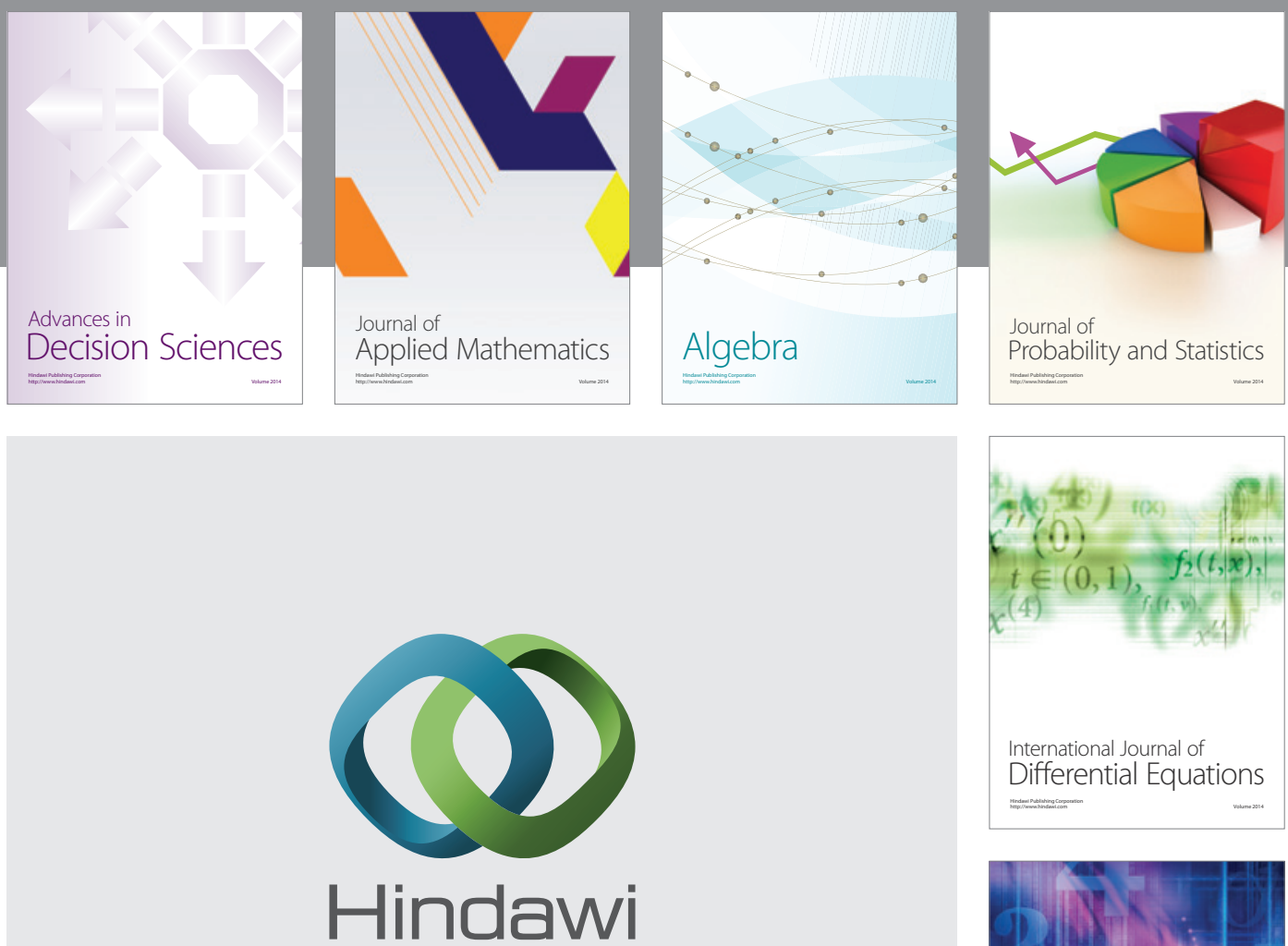

Submit your manuscripts at http://www.hindawi.com
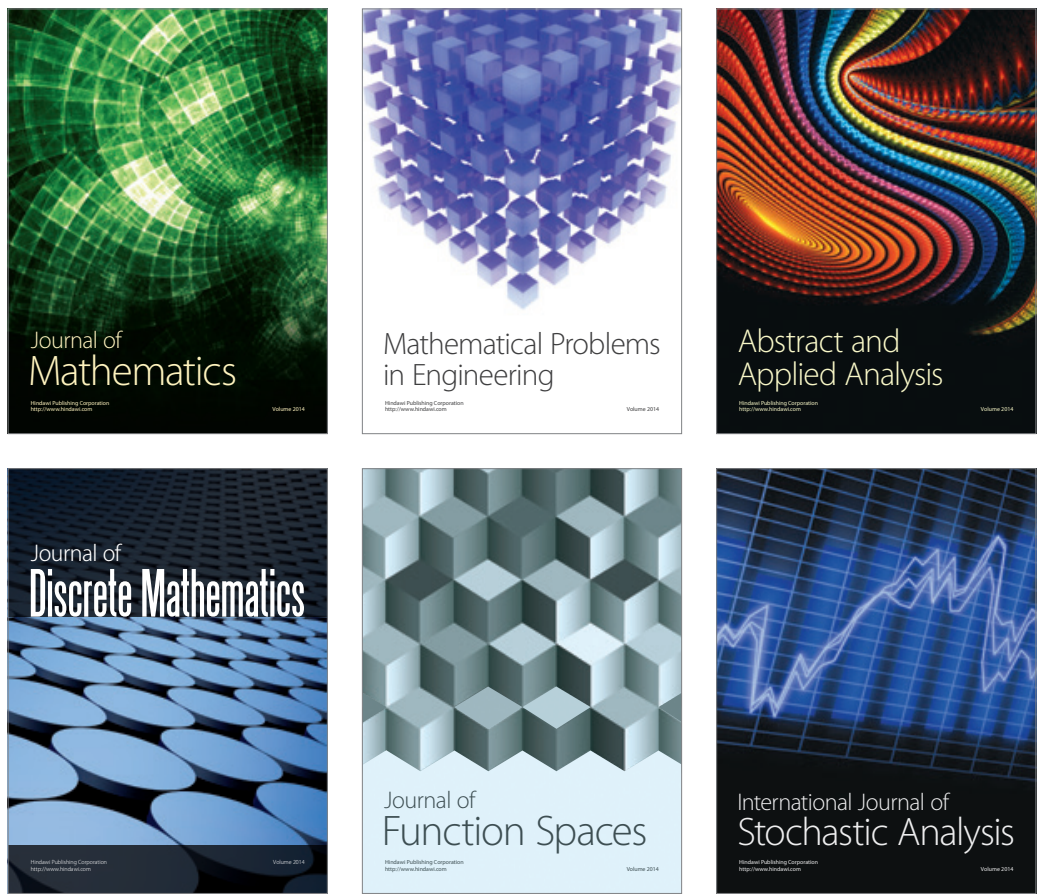

Journal of

Function Spaces

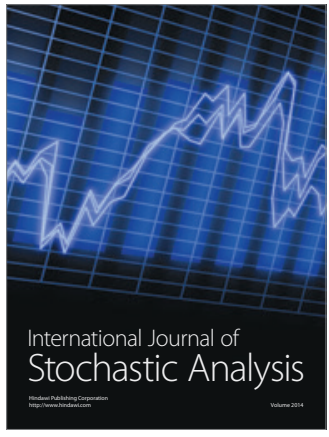

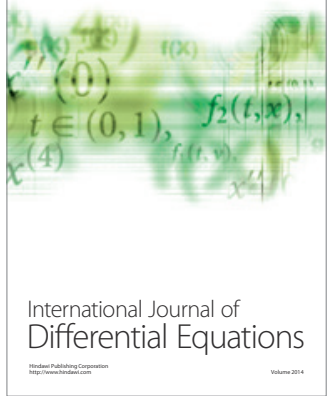
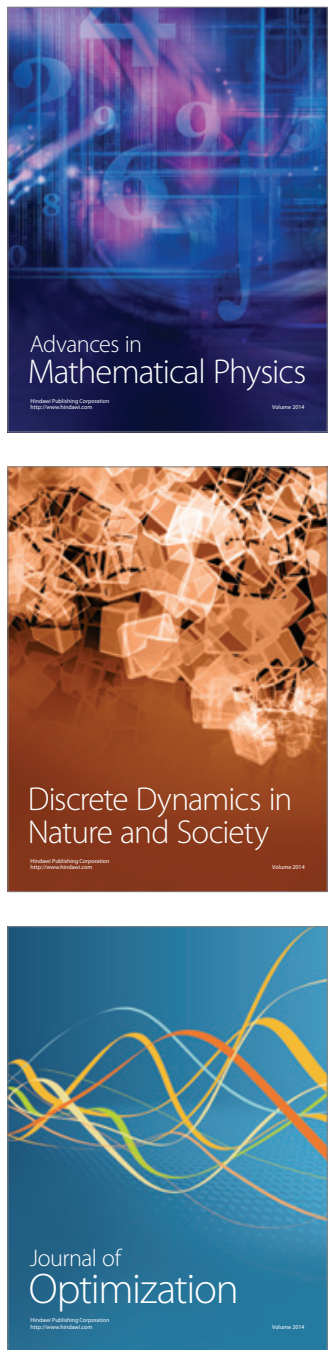